American Journal of Applied Sciences 6 (12): 2036-2042, 2009

ISSN 1546-9239

(C) 2009 Science Publications

\title{
Food-Related Lifestyle Segments in Taiwan: Application of the Food-Related Lifestyle Instrument
}

\author{
Cheng-Hsi Fang and Hwang-Jaw Lee \\ Department of Marketing and Distribution Management, Ching-Yun University, Taiwan
}

\begin{abstract}
Problem statement: This study applied the Food-Related Lifestyle (FRL) instrument for market segmentation in the Taiwan food sector. FRL instrument was originally developed by the Market-Based Product and Process Development in Danish (MAPP) research group, the instrument was adjusted for the Chinese food culture. The FRL instrument is wildly applied to empirical market analysis, especially in European nations. Its reliability and validity are also empirically proven. The present study serves as the first attempt to employ the FRL instrument to explore food-related lifestyle segments in Taiwan. Approach: A short questionnaire was issued to 650 Taiwanese consumers using quota sampling procedures and 565 valid responses were collected. Using the two-step cluster analysis, four distinct food-related consumer lifestyle segments were identified. Results: The four segments includes: traditional consumers $(23.54 \%)$, adventurous consumers $(27.61 \%)$, uninvolved consumers $(24.07 \%)$ and astute consumers $(24.78 \%)$. Conclusion/Recommendations: Comparison showed that these segments differ in their attitudes and behaviors towards food consumption. Profiles of the segments are achieved by observing the socio-demographic characteristics of typical segment members.
\end{abstract}

Key words: AIO, segmentation, instrument, VALS, food consumption

\section{INTRODUCTION}

The lifestyle concept has been wildly used in marketing research to assist companies with promotional strategies, customer segmentation and product development. Because lifestyle provides a lifelike view for classifying consumers into specific lifestyle patterns, it is used extensively to develop effective marketing strategies. Albeit widely used, the lifestyle concept is still quite controversial for two primary reasons: (1) Lifestyle has been used as a general term and there is no consensus in academia as to what the term lifestyle actually means ${ }^{[1,3]}$. In fact, lifestyle instruments are typically built by researchers on the basis of subjective induction rather than the result of deduction from related theories ${ }^{[1]}$. The resultant lack of a theoretical foundation for lifestyle causes numerous difficulties when attempting to compare the results of different researches ${ }^{[1]}$. (2) Human behaviors are so diverse that individual lifestyles are not necessarily consistent across different life domains. As most lifestyle instruments aim to measure individual Activities, Interests and Opinions (AIO) in nearly all aspects of life, lifestyle questionnaires typically involve hundreds of questions. As a result, such surveys become too general to explain consumer behaviors in specific areas.

To address this problem, Bruns $\varnothing$ and his colleagues $^{[4,5]}$ at the MAPP center in Denmark developed the food-Related Lifestyle Model (FRL) focused food choices in general. Based on the meansend chain theory, the authors successfully develop a cross-nationally validated food-related lifestyle instrument ${ }^{[3,14]}$. Thus far, their FRL instrument is applied to many European nations ${ }^{[3]}$, Australia ${ }^{[12]}$ and also to some Asian nations; such as Singapore and $J_{a p a n}{ }^{[12,15]}$. The present study serves as the first attempt to employ the FRL instrument to explore food-related lifestyle segments in Taiwan. Research results are expected to improve our understanding of food-related consumer behaviors in Taiwan and serve as a reference for enterprises to develop marketing strategies for foodrelated products in the country ${ }^{[9]}$.

Food-related lifestyle instrument: Food-related lifestyle, as developed by MAPP, is defined as the system of cognitive categories, scripts and their associations. It relates a set of products to a set of

Corresponding Author: Cheng-Hsi Fang, Department of Marketing and Distribution Management,

Ching-Yun University, Taiwan, 229, Chien-Hsin Rd., Jung-Li, Taiwan 320, Republic of China

Tel: 886-3-458-1196/ext 7512 Fax: 886-3-468-3994 
values $^{[9]}$. In order to provide theoretical background for lifestyle research, development of the FRL instrument was in strict accordance with a means-end chain approach. The dimensions to be measured were formulated in advance base on a sound theory; the research questionnaire was then developed accordingly. The means-end chain shows how the product characteristics are linked to the consequences of food consumption, the attainment of life values are connected subsequently. This approach regards lifestyle as a mental construct that explains, but is not identical to, actual behavior. Therefore, lifestyle becomes a concept that transcends individual brands or products, but may still be specific to a product class ${ }^{[9]}$. Development of the FRL instrument is deductive and considerably more rigorous than the predominating inductive approach in related lifestyle research. Further, items of the FRL questionnaire are tested by confirmatory factor analysis rather than traditional exploratory data analysis techniques.

The FRL model introduced by Bruns $\varnothing$ et al.$^{[6]}$ as shown in Fig. 1 which covers 23 dimensions in five interrelated domains. Each dimension includes three questions, so there are 69 questions in total. The five domains are:

- Way of shopping: This domain reflects consumer food shopping behaviors. There are six dimensions, including: The importance of product information, attitude toward advertising, joy of shopping, specialty shopping, price criterion and shopping list

- Quality aspects: This domain refers to what consumers demand from food consumption. Its 6 dimensions include: Health, price-quality relationship, novelty, organic products, tastiness and freshness

- Cooking methods: This domain examines such aspects as how products purchased are transformed into meals. The six dimensions of cooking methods include: Involvement with cooking, looking for new ways, convenience, family involvement, spontaneity and woman's task

- Consumption Situations: This domain concerns the situations in which consumers eat food. Two dimensions are included: Snacks versus meals and social events

- Purchasing motives: This domain examines what consumers expect from a meal and the importance of these expectations. Self-fulfillment, security and social relationships are three dimensions of this domain

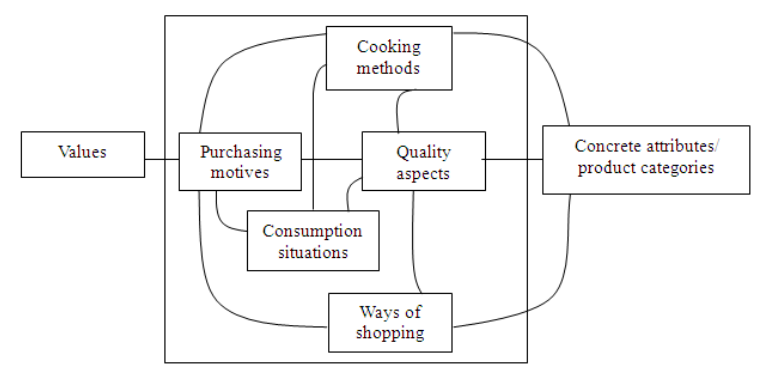

Fig. 1: Cognitive structures model for food-related lifestyles. Source: Brunsø and Grunert (1998)

The FRL instrument used for the present study is extensively tested in European nations. Its reliability and validity are also empirically proven ${ }^{[6,11]}$. Empirical results support that the measurement scale is invariant across Denmark, France, Germany, England and Australia. However, research in Singapore suggests that the dimensions and some items should be modified to fit Chinese culture ${ }^{[2]}$.

The FRL instrument is also wildly applied to empirical market analysis. For instance, Kesić and PiriRajh $^{[10]}$ used the FRL instrument to segment Croatian consumers into five groups: A "relaxed group" of consumers who are not interested in buying and preparing foods and reluctant to change eating habits; "traditionalists" who pay extra attention to foods and costs and generally are good cooks; a "modern group" of consumers who dislike spending time buying, preparing and cooking foods and wish to shorten shopping and cooking times; a "concerned group" of consumers prefer organic foods and avoid food products with additives; and "hedonists" who emphasize food freshness and enjoy eating, buying and cooking foods with friends and family.

Bruwer et al..$^{[7]}$ applied a modified FRL instrument to segment the Australian wine market into five different categories, each of which is characterized by different drinking habits. De Boer et al.$^{[8]}$ examined Irish consumers' purchasing behaviors for convenience food-related products to discover that fast and instant food consumers care about social activities most, like to try new tastes, new recipes and prepare various kinds of foods. They also hold positive attitudes toward advertising. Ryan et $a l^{[13]}$ employed the FRL instrument to segment Irish consumers into six groups to discover that the derived food-related lifestyle segments are similar across several nations. For instance, conservative and uninvolved consumer segments are included in all related studies, while adventurous and astute consumer segments also exist in many nations. 
Am. J. Applied Sci., 6 (12): 2036-2042, 2009

\section{MATERIALS AND METHODS}

Sample and sampling method: The FRL instrument comprises 69 items that measure 23 lifestyle dimensions within the five domains described above. All items are rated on a seven-point Likert-type scale, ranging from: (1) "completely disagree" to (7) "completely agree." A sample of 650 Taiwanese consumers is drawn on a household basis. The number of questionnaires distributed in each of four major counties is determined by the population ratio i.e., county vs. nation. In each household, the person who is responsible for food shopping and meal preparation was interviewed. In total, 565 valid responses are collected, which amounts to an $87 \%$ response rate. As shown in Table 1. Respondents are mostly female (78\%) and married $(71 \%)$. The primary age group is $31-44$ years old $(41 \%)$, followed by $45+$ year olds $(34 \%)$. In terms of education, subjects with a college degree or above accounted for the largest group (42\%).

Scale modification: According to Askegaard and Bruns $\varnothing^{[2]}$, the FRL instrument should be adjusted to fit into Chinese Collectivism culture. Therefore, after data were collected, the instrument was further adjusted using item analysis and exploratory factor analysis. Analysis was carried out using SPSS 10.0 for Windows. First, we performed item analysis to evaluate item-remainder correlation and internal consistency. Once a satisfactory coefficient alpha was achieved, exploratory factor analysis was used to confirm the uni-dimensionality of the construct. Table 2 demonstrates our modification of the FRL instrument. According to the results of factor analysis, the FRL instrument can be divided into 17 dimensions. Some dimensions in the original scale are combined into one dimension. For instance, "attitude toward advertising" and "specialty shopping" were combined into "reliance on experts"; "health" and "organic products" into "health and organic products"; "spending time" and "looking for new ways" into "involvement with cooking"; and "social relationships" and "self-fulfillment in food" into "social interaction and self-fulfillment". In the "ways of shopping" domain, the "shopping list" dimension is renamed "unscheduled shopping" because making a shopping list before purchasing food products is rare in Taiwan. In the "cooking methods" domain, the dimension of "spontaneity" was found to be insignificant and deleted from the scale.
Table 1: Respondents' demographic profiles

\begin{tabular}{lcc}
\hline Description & Frequency & Percentage \\
\hline Gender & 126 & \\
Male & 439 & 22.30 \\
Female & & 77.70 \\
Marital status & 401 & 70.97 \\
Married & 164 & 29.03 \\
Single & & \\
Age group & 141 & 24.96 \\
Under 30 & 234 & 41.42 \\
31-44 & 190 & 33.63 \\
Over 45 & & \\
Educational background & 182 & 32.21 \\
Less than high school & 147 & 26.02 \\
Junior college & 236 & 41.77 \\
Higher than college & & \\
Monthly household income (NTD) & & 16.99 \\
Less than \$40,000 & 96 & 21.06 \\
\$40,001-60,000 & 119 & 22.12 \\
\$60,001-80,000 & 125 & 16.11 \\
\$80,001-100,000 & 91 & 23.72 \\
Above \$100,001 & 134 &
\end{tabular}

Table 2: Modification of the FRL

\begin{tabular}{lll}
\hline Domains/dimensions & Item & Cronbach's alpha \\
\hline Ways of shopping & & \\
Importance of product information & 4 & 0.71 \\
Reliance on experts & 4 & 0.67 \\
Price criterion & 3 & 0.71 \\
Unscheduled shopping & 2 & 0.72 \\
Joy of shopping & 2 & 0.72 \\
Quality aspects & & \\
Health and organic products & 5 & 0.82 \\
Novelty & 5 & 0.78 \\
Price-quality relationship & 6 & 0.78 \\
Freshness & 2 & 0.64 \\
Cooking methods & & \\
Involvement with cooking & 6 & 0.77 \\
Convenience & 3 & 0.71 \\
Assistance from family & 2 & 0.66 \\
Woman's task & 2 & 0.50 \\
Consumption situations & & \\
Snacks versus meals & 3 & 0.55 \\
Social event & 3 & 0.60 \\
Purchasing motives & & \\
Social interaction and self-fulfillment & 6 & 0.71 \\
Security & 3 & 0.68 \\
\hline
\end{tabular}

\section{RESULTS}

Food-related lifestyle segments: To determine the optimal number of food-related lifestyle segments, a two-step cluster analysis was adopted. First, hierarchical cluster analysis was performed to calculate the Cubic Clustering Criterion (CCC) and the maximum value was selected as the relative optimal number of cluster. The K-means method was introduced with the optimal number, the final segments were obtained. This method can be used to avoid subjective explanation of cluster analysis and the instability of hierarchical clustering caused by data-sorting problems. 
Am. J. Applied Sci., 6 (12): 2036-2042, 2009

Table 3: Results of cluster analysis

\begin{tabular}{|c|c|c|c|c|c|c|c|c|c|c|}
\hline \multirow{3}{*}{$\begin{array}{l}\text { Domain/dimensions } \\
\text { Ways of shopping } \\
\text { Importance of product information }\end{array}$} & \multirow{3}{*}{$\begin{array}{l}\text { F ratio } \\
55.66\end{array}$} & \multirow{3}{*}{$\begin{array}{l}\mathrm{p} \text { - value } \\
0.00\end{array}$} & \multicolumn{2}{|c|}{ Cluster $1(23.54 \%)$} & \multicolumn{2}{|c|}{ Cluster $2(27.61 \%)$} & \multicolumn{2}{|c|}{ Cluster $3(24.07 \%)$} & \multicolumn{2}{|c|}{ Cluster $4(24.78 \%)$} \\
\hline & & & & & & & & & & \\
\hline & & & $0.39^{\mathrm{a}}$ & $(0.87)^{\mathrm{b}}$ & 0.18 & $(0.68)$ & -0.84 & $(1.04)$ & 0.24 & $(0.92)$ \\
\hline Reliance on experts & 54.83 & 0.00 & -0.09 & $(1.11)$ & 0.74 & $(0.76)$ & -0.27 & $(0.79)$ & -0.47 & $(0.84)$ \\
\hline Price criterion & 36.82 & 0.00 & -0.50 & $(1.11)$ & 0.22 & $(0.77)$ & -0.31 & $(0.88)$ & 0.53 & $(0.90)$ \\
\hline Unscheduled shopping & 23.52 & 0.00 & 0.46 & $(0.90)$ & -0.29 & (1.09) & -0.34 & $(0.76)$ & 0.21 & $(0.97)$ \\
\hline Joy of shopping & 21.50 & 0.00 & -0.03 & $(1.10)$ & 0.16 & $(0.82)$ & -0.52 & $(0.97)$ & 0.35 & $(0.91)$ \\
\hline \multicolumn{11}{|l|}{ Quality aspects } \\
\hline Health and organic products & 38.81 & 0.00 & 0.19 & $(1.00)$ & 0.55 & $(0.68)$ & -0.43 & $(0.79)$ & -0.37 & (1.13) \\
\hline Novelty & 113.5 & 0.00 & -0.90 & $(1.01)$ & 0.63 & $(0.61)$ & -0.31 & $(0.76)$ & 0.46 & $(0.77)$ \\
\hline Price-quality relation & 92.56 & 0.00 & 0.43 & $(0.80)$ & 0.03 & $(0.69)$ & -0.97 & $(1.00)$ & 0.50 & $(0.78)$ \\
\hline Freshness & 25.86 & 0.00 & 0.33 & $(0.88)$ & 0.31 & $(0.86)$ & -0.51 & $(0.91)$ & -0.16 & (1.10) \\
\hline \multicolumn{11}{|l|}{ Cooking methods } \\
\hline Involvement with cooking & 42.42 & 0.00 & -0.41 & $(0.96)$ & 0.45 & $(0.77)$ & -0.49 & $(0.92)$ & 0.37 & $(0.98)$ \\
\hline Convenience & 49.04 & 0.00 & -0.62 & $(0.83)$ & 0.37 & $(1.06)$ & 0.49 & $(0.78)$ & -0.30 & $(0.85)$ \\
\hline Assistance from family & 13.73 & 0.00 & 0.02 & $(0.95)$ & 0.33 & $(0.95)$ & -0.40 & $(0.92)$ & -0.01 & $(1.04)$ \\
\hline Woman's task & 41.07 & 0.00 & 0.27 & $(0.88)$ & 0.43 & $(0.98)$ & -0.08 & $(0.82)$ & -0.66 & $(0.94)$ \\
\hline \multicolumn{11}{|l|}{ Consumption situations } \\
\hline Snacks versus meals & 58.92 & 0.00 & -0.33 & $(0.77)$ & 0.63 & $(0.98)$ & 0.23 & $(0.89)$ & -0.61 & $(0.83)$ \\
\hline Social event & 41.27 & 0.00 & -0.73 & $(1.07)$ & 0.34 & $(0.85)$ & 0.01 & $(0.88)$ & 0.31 & $(0.83)$ \\
\hline \multicolumn{11}{|l|}{ Purchasing motives } \\
\hline $\begin{array}{l}\text { Social interaction and } \\
\text { self-fulfillment }\end{array}$ & 101.8 & 0.00 & -0.50 & $(0.86)$ & 0.57 & $(0.69)$ & -0.73 & $(0.92)$ & 0.55 & $(0.76)$ \\
\hline Security & 65.18 & 0.00 & -0.05 & $(0.94)$ & 0.59 & $(0.88)$ & 0.18 & $(0.75)$ & -0.78 & $(0.88)$ \\
\hline
\end{tabular}

The analyzed results allow us to distinguish four different segments of food-related lifestyles of Taiwanese families. Table 3 shows these four segments and the result of ANOVA on the 17 dimensions. Post hoc Scheffe's test confirmed that the differences between groups were significant. Thus, it can be inferred that the segmentation of the sample data into four clusters is appropriate. We further calculated the means and standard deviations of each dimension. Groups are labeled according to the segment's primary characteristics and based on similar food-related clusters identified by earlier studies. The following four clusters are named and explained as follows:

Segment 1: Traditional food consumers: A total of 133 participants $(23.54 \%)$ are included in this segment. Consumers in this segment are quite traditional in their shopping and cooking behaviors; they tend to pay extra attention to product labels before purchases, but are also involved in many impulsive purchases. In fact, their price consciousness is the lowest of all segments. That doesn't mean that they care less about how much they pay for food products, they simply don't buy the cheapest products but pay extra attention to the price/quality relationship.

In terms of quality aspects, traditional food consumers appreciate the freshness of foods. However, they are far less interested in novelty products; these individuals avoid trying foods which they are not familiar with. As to cooking methods, traditional food consumers are more conservative and dislike changing their ways of cooking. They don't like to use instantfood or ready-to-eat foods. Moreover, consumers in this segment seldom dine out with friends and do not think that they can obtain self-fulfillment and achievement from cooking.

Segment 2: Adventurous food consumers: The adventurous food consumers segment of the individuals under study comprises 156 people $(27.61 \%)$ of the sample. Consumers in this segment prefer advertised food products and like to buy foods in specialty shops with the assistance of a salesperson. In general, these consumers are interested in all food-related activities; they are price consciences to certain degrees, they usually do research before making purchase decisions. In terms of quality, they have strong preferences for organic and healthy foods; however, they also like to taste various exotic cuisines and emphasize the importance of food tastes.

In terms of cooking methods, compared to other segments, adventurous food consumers are most keen on cooking and open to creativities and challenges in cooking. However, most of them conceived that the whole cooking process to be the woman's job. In fact, these individuals consider the kitchen a woman's domain. Food and food products are very important parts of their lives; they enjoy eating out with friends and snack regularly. With respect to motives, this group considers dining with friends or family an important social activity and is proud if complimented on their food. 
Am. J. Applied Sci., 6 (12): 2036-2042, 2009

Table 4: Demographic characteristics of consumers in identified segments

\begin{tabular}{|c|c|c|c|c|c|}
\hline Consumers & Traditional & Adventurous & Uninvolved & Astute & All \\
\hline \multicolumn{6}{|l|}{ Gender } \\
\hline Male & $18(13.53)$ & $34(21.79)$ & $47(34.56)$ & $27(19.29)$ & $126(22.30)$ \\
\hline Female & $115(86.47)$ & $122(78.21)$ & $89(65.44)$ & $113(80.71)$ & $439(77.70)$ \\
\hline \multicolumn{6}{|l|}{ Marital status } \\
\hline Married & $114(85.71)$ & $114(73.08)$ & $86(63.24)$ & $87(62.14)$ & $401(70.97)$ \\
\hline Single & $19(14.29)$ & $42(26.92)$ & $50(36.76)$ & $53(37.86)$ & $164(29.03)$ \\
\hline \multicolumn{6}{|l|}{ Age } \\
\hline Under 30 & $10(7.52)$ & $32(20.51)$ & $54(39.71)$ & $45(32.14)$ & $141(24.96)$ \\
\hline $31-44$ years old & $45(33.83)$ & $76(48.72)$ & $59(43.38)$ & $54(38.57)$ & $234(41.42)$ \\
\hline Over 45 years old & $78(58.65)$ & $48(30.77)$ & $23(16.91)$ & $41(29.29)$ & $190(33.63)$ \\
\hline \multicolumn{6}{|l|}{ Occupation } \\
\hline Governmental employee and military & $36(27.07)$ & $39(25.00)$ & $32(23.53)$ & $44(31.43)$ & $151(26.73)$ \\
\hline Worker & 19 (14.29) & $26(16.67)$ & $25(18.38)$ & $16(11.43)$ & $86(15.22)$ \\
\hline Household person & $42(31.58)$ & $26(16.67)$ & $20(14.71)$ & $30(21.43)$ & $118(20.88)$ \\
\hline Private company employee & $24(18.05)$ & $38(24.36)$ & $32(23.53)$ & $32(22.86)$ & $126(22.30)$ \\
\hline Other $T$ & $12(9.02)$ & $27(17.31)$ & $27(19.85)$ & $18(12.86)$ & 84 (14.87) \\
\hline \multicolumn{6}{|l|}{ Education background } \\
\hline Less than high school & $62(46.62)$ & $58(37.18)$ & $34(25.00)$ & $28(20.00)$ & $182(32.21)$ \\
\hline Junior college & $35(26.32)$ & $48(30.77)$ & $29(21.32)$ & $35(25.00)$ & $147(26.02)$ \\
\hline Higher than college & $36(27.07)$ & $50(32.05)$ & $73(53.68)$ & $77(55.00)$ & $236(41.77)$ \\
\hline \multicolumn{6}{|l|}{ Household structure } \\
\hline No children & $10(7.52)$ & $31(19.87)$ & $43(31.62)$ & $35(25.00)$ & $119(21.06)$ \\
\hline Youngest child under 5 years old & $16(12.03)$ & $27(17.31)$ & $23(16.91)$ & $19(13.57)$ & $85(15.04)$ \\
\hline Youngest child between 6-18 years old & $50(37.59)$ & $50(32.05)$ & $30(22.06)$ & $40(28.57)$ & $170(30.09)$ \\
\hline Youngest child over 18 , living with parents & $49(36.84)$ & $40(25.64)$ & $31(22.79)$ & $39(27.86)$ & $159(28.14)$ \\
\hline No children at home & $8(6.02)$ & $8(5.13)$ & $9(6.62)$ & $7(5.00)$ & $32(5.66)$ \\
\hline
\end{tabular}

Segment 3: Uninvolved food consumers: Based on the sample, a total of 136 consumers $(24.07 \%)$ are in this segment. On the whole, these consumers are less interested in any food-related activities. They show little interest in any kind of food-related information and are insensitive to price fluctuations. In fact, they do not like shopping. Consumers in this segment care much less about taste, healthiness, freshness or the price/quality relationship of food, than other consumers. Not surprisingly, this group doesn't want to waste much time on cooking and are the ones most interested in quick and easy cooking methods. Thus, uninvolved food consumers typically purchase instant or frozen foods and also prefer ready-to-eat products. They sometimes eat snacks to cover regular meals and seldom change their dietary habits.

Segment 4: Astute food consumers: This segment comprises 140 individuals of the sample (24.78\%). These consumers enjoy shopping, care about product information, but are not affected by advertisements. Compared to other consumers, these individuals score high on price consciousness and are very sensitive to price fluctuations. They don't buy food simply based on word-of-mouth referrals. With regard to quality aspects, the most important factor to these individuals is the price/quality relationship; they are not interested in healthy, fresh, natural and ecological products, whereas taste is very important to them. These consumers also enjoy cooking and love to try new recipes. They do not think that cooking should be quick and easy. Moreover, astute food consumers are strongly against the idea that cooking is solely a woman's task. This group has the lowest tendency to snack, but they like to eat out with friends. Self-fulfillment and social relationship are important purchasing motives.

Demographic analysis of food-related lifestyle segments: The food-related lifestyle segments derived from the modified FRL instrument show significant differences with respect to demographic variables. As shown in Table 4, in the traditional consumer segment, the ratio of female consumers is approximately $10 \%$ more than the average; with regard to uninvolved food consumers, male consumers comprise $12 \%$ more than the average. In terms of marital status, uninvolved and astute food consumers comprise higher proportions of unmarried consumers, while traditional consumers have a higher proportion of married consumers. With respect to age and occupation, traditional food consumer segment comprises mainly female consumers over 45 years old $(58.65 \%)$, who are older than the average age of all segments. Most of them are housewives.

People in the adventurous consumer segment are concentrated in the 31-44 years old age group. They are typically career women who devote themselves to their families and jobs. Consumers in the uninvolved and astute consumer segments are slightly younger than 
other consumers. In terms of education, traditional food consumer segment has a lower level of education, on average, whereas the uninvolved consumer segment and astute consumer segment comprise a high proportion of individuals who holds a degree above the college education level. In terms of family composition, most traditional consumers have family members aged 6-18 years in their households. Uninvolved consumers significantly include individuals with no children.

\section{DISCUSSION}

This study modified the FRL instrument into 17 food-related dimensions of five domains. Based on a modified-FRL instrument, food-related lifestyle segments in Taiwan are empirically explored. Using a two-step cluster analysis, we identify four distinctive food-related lifestyle segments, which include: (1) traditional consumer segment (23.54\%); (2) adventurous consumer segment (27.61\%); (3) uninvolved consumer segment (24.07\%) and (4) astute consumer segment (24.78\%). The number of adventurous consumers in the study group slightly outnumbers those in other segments; however, the difference is not significant.

The uninvolved and adventurous consumer segments are of two extreme lifestyles. Uninvolved food consumers pay little attention to food-related consumption; their primary concern is convenience. By contrast, adventurous consumers pay careful attention to each food-related dimension; they prefer healthy and organic food products, but also like to taste different kinds of food. Adventurous consumers even used instant food or ready-to-eat foods from time to time. In addition, these individuals carefully read the information on product labels (second only to traditional consumers) but still are easily affected by advertisements and the recommendations of salespersons. In sum, adventurous consumers hold open attitudes toward any kind of food-related activities.

Traditional food consumers less frequently dine out and dislike trying novel or exotic foods. They are also not sensitive to price fluctuations and care most about food freshness. Astute food consumers also value product information, but show little trust of the advertisements or recommendations from the salesperson. Having the highest level of price awareness, they are likely to accurately estimate whether or not every penny spent is worthwhile and effective. In addition, as a group, they show the most interest in food shopping.

The study also provides demographic profiles for each segment, the results of which can serve as a reference for companies to use when developing marketing strategies and planning for market campaigns. For instance, the uninvolved consumer segment comprising mostly male bachelors, it may not be necessary to stress on advertising. Instead, food companies should focus on product designs to provide easy-to-use food products. For traditional consumers, food companies should pay attention to the design of product labels since consumers in this group are reliant on product labels and they usually have unplanned purchase behaviors. The study found that adventurous consumers are enthusiastic for almost all part of foodrelated activities. They not only like to try new products but also enjoy sharing their food with friends. Thus, they play an important role in diffusion of product information.

The FRL instrument used in the present study is extensively applied by extant literature in the analysis of consumer segments in European nations. In these regions, there are typically 4-6 segments developed. This study adopts Cubic Clustering Criterion (CCC) to determine the relatively optimal number of clusters. Such an approach allows the avoidance of criticism over subjective clustering. However, the segments derived in this study share several similarities with those obtained in other studies. For example, Bruns $\varnothing$ et al. ${ }^{[6]}$ performed analysis of cross-cultural segmentation in Denmark, France, Germany and England to discover that, except for France, all other nations studies have identified "exploratory" and "uninvolved" consumers. The characteristics of these two segments are similar to those of the "adventurous" and "uninvolved" segments identified in this study. Moreover, the "rational" consumer segment exists in all four nations. This segment resembles the "astute" consumer segment in this study; the only difference lies in the quality aspects. Rational consumers care about healthy and organic foods while astute consumers pay careful attention to novelty and tastes. The "conservative" consumer segment also is frequently observed in many nations. This segment is related to the traditional consumer segment from this study. The notable differences are: the conservative consumers tend to pay more attention to low price and be more sensitive to price fluctuation. They like to cook and obtain self-fulfillment from preparing food for their family. However, in this study, traditional consumers are least price sensitive and do not expect to obtain satisfaction from cooking. They do not like to change their diet or pursue new tastes.

\section{CONCLUSION}

This study has important implications for researchers and practitioners alike. First of all, the 
similar results found in this study again confirmed the cross-cultural validity of the FRL instrument. For an international food company, FRL instrument serve as a useful tool to target their products in global market. Secondly, this study compared results from different cultural settings. We suggested that the FRL instrument could be further simplified into a smaller scale which is easier to apply and still provides enough information for companies to develop marketing strategies.

\section{REFERENCES}

1. Anderson, W.T. and L.L. Golden, 1984. Life style and psychographics: A critical review and recommendation. Adv. Consum. Res., 11: 405-411. DOI: $10.1021 /$ es0497375

2. Askegaard, S. and K. Brunsø, 1999. Food-related life styles in Singapore: Preliminary testing of a western European Research instrument in Southeast Asia. J. Euromarket., 7: 65-86. DOI: 10.1300/J037v07n04_04

3. Brunsø, K. and K.G. Grunert, 1998. Cross-cultural similarities and differences in shopping for food. J. Bus. Res., 42: 145-150. DOI: 10.1016/S01482963(97)00114-8

4. Brunsø, K. and K.G. Grunert, 1995. Development and testing of a cross-culturally valid instrument: Food-related life style. Adv. Consum. Res., $\quad 22$ : 475-480. http://rpa.lib.cyu.edu.tw:2051/login.aspx?direct=tru e\&db=bth\&AN=9509150096\&amp;lang=zhtw\&site $=$ ehost-live

5. Bruns $\varnothing$, K., J. Scholderer and K.G. Grunert, 2004. Testing relationships between values and foodrelated lifestyle: Results from two European countries. Appetite, 43: 195-205. DOI: 10.1016/j.appet.2004.05.001

6. Bruns $\varnothing$, K., J. Scholderer and K.G. Grunert, 2004. Closing the gap between values and behavior-a means-end theory of lifestyle. J. Bus. Res., 57: 665-670. DOI: 10.1016/S0148-2963(02)00310-7

7. Bruwer, J., E. Li and M. Reid, 2002. Segmentation of the Australian wine market using a wine-related lifestyle approach. J. Wine Res., 13: 217-242. DOI: $10.1080 / 0957126022000046510$
8. de Boer, M., M. McCarthy, C. Cowan and I. Ryan, 2004. The influence of lifestyle characteristics and beliefs about convenience food on the demand for convenience foods in the Irish market. Food Qual. Prefer., 15: 155-165. DOI: 10.1016/S09503293(03)00054-5

9. Grunert, K., K. Brunsø and S. Bisp, 1997. FoodRelated Lifestyle: Development of a CrossCulturally Valid Instrument for Market Surveillance. In: Values, Lifestyles and Psychographics, Kahle, L. and C. Chiagouris (Eds.). Erlbaum, Mahwah, pp: 337-354. http://research.asb.dk/fbspretrieve/88/wp12.pdf

10. Kesić, T. and S. Piri-Rajh, 2003. Market segmentation on the basis of food-related lifestyles of Croatian families. Br. Food J., 105: 162-174. DOI: $10.1108 / 00070700310477112$

11. O'Sullivana, C., J. Scholderer and C. Cowan, 2005. Measurement equivalence of the Food Related Lifestyle instrument (FRL) in Ireland and Great Britain. Food Qual. Prefer., 16: 1-12. DOI: 10.1016/j.foodqual.2003.12.002

12. Reid, M., E. Li, J. Bruwer and K. Grunert, 2001. Food-related life styles in a cross-cultural context: Comparing Australia with Singapore, Britain, France and Denmark. J. Food Prod. Market., 7: 57-75. DOI: 10.1300/J038v07n04_05

13. Ryan, I., C. Cowan, M. McCarthy and C. O'Sullivan, 2004. Segmenting Irish food consumers using the food-related lifestyle instrument. J. Int. Food Agribusi. Market., 16: 89-114. DOI: 10.1300/J047v16n01_06

14. Scholderer, J., K. Brunsø, L. Bredahl and K.G. Grunert, 2004. Cross-cultural validity of the Food-Related Lifestyles instrument (FRL) within Western Europe. Appetite, 42: 197-211. DOI: 10.1016/J.APPET.2003.11.005

15. Shim, S., K. Gehrt and S. Lotz, 2001. Export implications for the Japanese fruit market: Fruitspecific lifestyle segments. Int. J. Retail Distribut. Manage., $\quad 29$ : 300-316. $\quad$ DOI: $10.1108 / 09590550110393983$ 